Int. J. Electrochem. Sci., 15 (2020) $382-393$

International Journal of

ELECTROCHEMICAL

SCIENCE

www.electrochemsci.org

\title{
Effect of N-N Dimethyltrifluoroacetamide Additive on Low Temperature Performance of Graphite Anode
}

\author{
Wenqing Zuo ${ }^{1,2,3}$, Yongli Cui ${ }^{1,2,3, *}$, Quanchao Zhuang ${ }^{1,2,3}$, ,Yueli Shi ${ }^{1,2,3,}$ Pengzhan Ying ${ }^{1,2,3, *}$, Yanhua \\ $\mathrm{Cui}^{4}$ \\ ${ }^{1}$ Li-ion Batteries Lab, School of Materials Science and Engineering, China University of Mining \& \\ Technology, Xuzhou 221116, China \\ ${ }^{2}$ The Jiangsu Province Engineering Laboratory of High Efficient Energy Storage Technology and \\ Equipments under grant no. [2017]975-18 \\ ${ }^{3}$ The Xuzhou City Key Laboratory of High Efficient Energy Storage Technology and Equipments \\ under grant no. KH17078 \\ ${ }^{4}$ Institute of Electronic Engineering China Academy of Engineering Physics, \\ Mianyang, 621000, P. R. China \\ *E-mail: lilyshuoxu@163.com
}

doi: $10.20964 / 2020.01 .08$

Received: 27 May 2019 / Accepted: 5 July 2019 / Published: 30 November 2019

The effects of N-N Dimethyltrifluoroacetamide (DTA) on the low temperature performance of Li-ion batteries were evaluated, electrolyte ionic conductivity test, charge-discharge, cyclic voltammetry (CV), scanning electron microscope (SEM), X-ray photoelectron spectroscopy (XPS) and electrochemical impedance spectroscopy (EIS) were used to analyze the electrochemical processes. The results showed that the first charge capacities of the graphite electrode in the electrolyte without and with DTA were 72.2 and $114.6 \mathrm{mAh} \mathrm{g}^{-1}$ at $-20^{\circ} \mathrm{C}, 325.1$ and $370.8 \mathrm{mAh} \mathrm{g}^{-1}$ at $20^{\circ} \mathrm{C}$, respectively. After 100 cycles, the corresponding capacities fade to 64.5 and $108.72 \mathrm{mAh} \mathrm{g}^{-1}$ at $-20^{\circ} \mathrm{C}, 299.5$ and $348.5 \mathrm{mAh} \mathrm{g}^{-1}$ at $20^{\circ} \mathrm{C}$, and the capacity retention were $88.7 \%$ and $94.8 \%$ at $-20^{\circ} \mathrm{C}, 92.12 \%$ and $93.9 \%$ at $20^{\circ} \mathrm{C}$, respectively. The first Coulomb efficiency in the electrolyte with and without DTA was $87.41 \%$ and $83.37 \%$ at $20^{\circ} \mathrm{C}$, respectively. The electrolyte ionic conductivity test shows DTA increases the ionic conductivity of 1mol/L LiPF 6 2:1:4 (vol.\%) EC/DEC/EMC. The SEM and XPS showed that DTA additive make the SEI film become more dense and uniform and reduce the content of the unstable substance alkyl lithium carbonate and increase the content of $\mathrm{LiF}$ in the SEI film at $-20^{\circ} \mathrm{C}$. EIS results demonstrated that the SEI resistance of the Li/graphite batteries with DTA was far smaller than those without DTA, especially at $-20^{\circ} \mathrm{C}$. The improved electrochemical performance with DTA was attributed to the enhancement of the conductivity of the electrolyte, the decrease of the SEI resistance. 
Keywords: Lithium-ion batteries; low temperature; N-N Dimethyl Trifluoroacetamide additive; Solid electrolyte interface (SEI) film

\section{$\underline{\text { FULL TEXT }}$}

(C) 2020 The Authors. Published by ESG (www.electrochemsci.org). This article is an open access article distributed under the terms and conditions of the Creative Commons Attribution license (http://creativecommons.org/licenses/by/4.0/). 